\title{
ENLARGEMENTS AND THE PRINCIPLES OF DESIGNING EU DECISION-MAKING PROCEDURES
}

\author{
MIKA WIDGRÉN \\ CESIFO WORKING PAPER No. 903 \\ CAtegory 2: Public CHOICE \\ APRIL 2003
}

Presented at CESifo Conference "A Constitution for the EU”, Febrary 2003

\footnotetext{
An electronic version of the paper may be downloaded

- from the SSRN website: www.SSRN.com

- from the CESifo website: www.CESifo.de
} 


\title{
ENLARGEMENTS AND THE PRINCIPLES OF DESIGNING EU \\ DECISION-MAKING PROCEDURES
}

\begin{abstract}
This paper examines how neutral the current EU decision-making procedures are to membership and how well they obey certain transparent general constitutional principles. The paper evaluates the performance of the procedures by strategic and classical power indices. The main emphasis in the assessment is in stability, efficiency and fairness. The paper concludes that co-decision either with shared right to initiate between the Commission and the the Parliament or a double-hat Presidency works the best. In the Council the current weighting should be replaced by the dual majority of square-rooted populations and Member States.
\end{abstract}

JEL Code: C71, C72, D71, D72.

\author{
Mika Widgrén \\ Turku School of Economics \\ and Business Administration \\ Rehtorinpellonkatu 3 \\ 20500 Turku \\ Finland \\ mika.widgren@tukkk.fi
}

Revised version of the paper presented at CES conference "Constitution for the European Union" in Munich 7-8 February 2003. I am grateful for Gerrit Köster and the conference participants for beneficial comments and for Stefan Napel for useful discussions that have benefited this work. 


\section{Introduction}

Experiences on earlier enlargements and especially the Nice reforms demonstrate that the design of decision-making procedures and voting rules in EU institutions belong to the most cumbersome parts of membership negotiations. Since the institutional arrangements and decision-making in the EU are not based on clear constitutional rules this creates unnecessary additional costs for enlargements and potential secession. The lack of underlying principles in the design of decision-making rules also unnecessarily increases pressures and demands to re-negotiate the rules.

The Nice Summit in December 2000 confirms the difficulties that may arise when enlargements and institutional reforms are tied together. ${ }^{1}$ The main argument behind the need of the reform was the fact that large member states have weaker representation and less power in the Council than their share of EU population would suggest while for the smallest countries the reverse holds. Since the current candidate countries are mainly small nations the problem was seen more urgent in the eyes of EU leaders than before. This started the reform process soon after the 1995 enlargement. ${ }^{2}$ In the Council of Ministers, the Treaty of Nice introduced the first re-weighting of member states' voting rights since the establishment of the European Community in $1957 .{ }^{3}$

\footnotetext{
${ }^{1}$ In the case of eastern enlargement the Treaty of Nice defines candidate countries' voting rights in the Council and numbers of seats in the European Parliament and consequent vote threshold in the Council. Strictly speaking, the latter is, however, defined for EU27 and this must still be negotiated since only 10 new countries will join in the first phase in May 2004. Possible rejection of the Accession Treaty in any candidate country would require still another negotiation round.

${ }^{2}$ Note that there was a debate on votes in the Council before Austria's, Finland's and Sweden's entry as well. That finally led to so-called Ionnina compromise whereby 23 votes minority of the total 87 votes in the Council can postpone the acceptance of a proposal by three months and put in under reconsideration. Qualified majority that is needed for passage of a proposal is 62 votes, i.e. 71 per cent. The compromise was a result of some member states' claims for increasing the quota to 65 out of 87 votes, i.e. nearly 75 per cent.

${ }^{3}$ In 1973 the original numbers of votes were multiplied by 2.5 and Luxembourg's votes only by 2. This, of course had a small re-weighting effect as well. Since 1973 the incumbent countries' numbers of votes
} 
Although the determination of voting rights in the Council looks automatic, in practise, it far from that. With this respect there are three striking features, first, new entrants' voting rights have always been negotiated as a part of their accession treaties and, second, as the system - both before and after Nice - puts member states into categories all countries within one category having the same number of votes, the assignment of groups to the new entrants have always been a tough question in membership negotiations. ${ }^{4}$ Third striking aspect is the fact that the current system, still in power till the enlargement, has not been updated to reflect changes in member states relative sizes. ${ }^{5}$ In sum, it seems that eastern enlargement was used to reform (and update) the system without regarding the two first shortcomings of the system.

As the entry of new member states requires incumbent countries' unanimous agreement, threats of vetoing a candidate country's entry can be used to gain in negotiations on required reforms in institutional rules or in general in EU decision-making. To avoid the bias to decision-making institutions caused by the seek of short run gains the task of the constitution is to design the institutional structure and the decision-making rules using acceptable transparent principles that are neutral to changes in membership and that can be automatically revised if the basis of these principles change.

The objective of this paper is to assess EU decision-making procedures and, related to them, two well-known principles of designing legitimate institutions in terms of their neutrality to membership. We argue that the constitutional rules should obey the following two principles

- The EU as a union of states and a union of citizens

- One person one vote principle.

have remained the same.

${ }^{4}$ In terms of their populations, Sweden and Austria are rather close to middle sized countries having five votes each. They also had this as their goal in membership negotiations. A new category of four votes was, however, established (see Hamilton 1991 or Widgrén 1994 for a more detailed discussion).

${ }^{5}$ The best example is the Netherlands where the size of the population has increased by 60 per cent since the times of the Treaty of Rome. See also Laruelle \& Widgrén (1998). 


$$
\text { Ex ante Expost }
$$

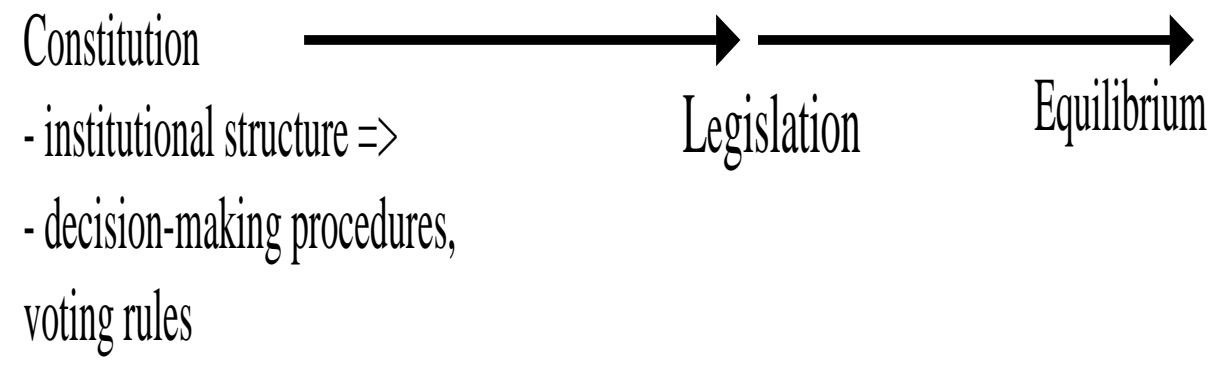

Figure 1: The structure of analysis

In a federation the former gives equal weights to the union of states legitimacy and the union of citizens legitimacy. In a confederation the latter gets a lower weight and in purely inter-governmental approach it diminishes to zero.

Figure 1 gives the structure of our analysis. We assume that the constitution gives general desirable goals for the institutional structure in the EU and the consequent decisionmaking rules, i.e. procedures, voting rights and majority rules, are defined to achieve the goals. Examples of the former could be like "all EU citizens should be equally represented" or "the European Parliament and the Council should be equal decision-makers". The equilibrium analysis is then carried out to analyze the policy implications of the legislative procedures and ex ante assessment of the equilibrium analysis reveals on what kind of principles the legislative procedures are built upon and how stable or neutral to membership these principles are.

\section{The Tools}

Our starting point is that the constitution should be defined based on general desirable, stable and transparent goals for the institutional structure and and the consequent more detailed decision-making rules in the EU. More detailed procedures, voting rights and majority rules, are then defined to achieve the goals. Examples of the former could be 
like "all EU citizens should be equally represented" or "the European Parliament and the Council should be equal decision-makers". As these examples demonstrate, influence is a crucial element in any decision-making institution. The role of the decision-making rules or, more generally, institution design is to affect power relations in institutions where decisions are made.

Theoretically, quantitative analysis of decision-making rules can be divided into two approaches: methods based on co-operative games and, on the other hand, non-cooperative games. Recently, there has been a lively debate between two schools of thought on the appropriate tools that should be used to assess and design different constitutional decisionmaking rules. Scholars of co-operative game theory apply different power indices mainly for assessing the implications of different decision-making rules on actors' influence in decisionmaking. The considered agents have no particular preferences and form winning coalitions which then implement, in the analysis, unspecified policies. Individual chances of being part of and influencing a winning coalition are then measured by a power index. ${ }^{6}$

The second approach uses non-cooperative game theory to analyze the impact of explicit decision procedures and given preferences over a well-defined - usually Euclidean - policy space. $^{7}$ In this approach conclusions are based on equilibrium analysis, which requires more detailed information regarding the players' preferences. As such non-cooperative approach does not fit analysis of constitutional rules but by considering several realizations of actors' preference constellations one is able to draw conclusions on performance of the constitutional rules. This unified approach can also be seen as a bridge between the two distinct approaches. ${ }^{8}$

Co-operative approach fits to institution design when the rules are understood simply as voting weights and vote threshold that is required for the passage of a proposal. That is

\footnotetext{
${ }^{6}$ See e.g. Laruelle and Widgrén (1998), Baldwin et al. (2000, 2001), Felsenthal and Machover (2001), and Leech (2002) for recent applications of traditional power indices. Felsenthal and Machover (1998) and Nurmi (1998) contain a more general discussion regarding index-based analysis of power.

${ }^{7}$ See e.g. Steunenberg (1994), Tsebelis (1994, 1996), Crombez (1996, 1997), and Moser (1996, 1997).

${ }^{8}$ See Steunenberg et al. 1999, Napel and Widgrén 2002, 2003.
} 
why these methods fit e.g. to assessment of the distribution of power in a single decisionmaking body like the Council. Among the co-operative concepts perhaps the most often used tool in analysis of constitutional rules is the Penrose-Banzhaf measure (PBM), ${ }^{9}$ which can be written as

$$
\beta_{i}=\sum_{S \in \mathcal{M}_{i}}\left(\frac{1}{2}\right)^{n-1}
$$

where $\mathcal{M}_{i}$ refers to a vulnerable majority coalition with respect to player $i$, i.e. a winning coalition in which $i$ has a swing position. The PBM can be interpreted as player $i^{\prime} s$ probability of being in the position to swing the coalition from winning to losing. Power is, thus, defined as one's ability to contribute to the existing state of affairs. To assess relative power the PBM is often normalized and then referred to as the (normalized) Banzhaf index (NBI). It can be written as follows

$$
\beta_{i}^{\prime}=\frac{\sum_{S \in \mathcal{M}_{i}}\left(\frac{1}{2}\right)^{n-1}}{\sum_{j=1}^{n} \sum_{S \in \mathcal{M}_{j}}\left(\frac{1}{2}\right)^{n-1}} .
$$

Note that swings are defined based on players' positions in coalitions but the NBI gives a player's share of all swings as defined above.

Inter-institutional aspects play a significant role in the design of decision-making rules and procedures. For instance, the EU Treaties define explicitly the actors that are involved in decision-making and the procedures and in which way, i.e. the sequence of moves, of how decisions are made. This also means that procedural aspects are important since the sequence in which the main institutions act in decision-making is defined as a part of the voting rules.

The major drawbacks of the established power indices of cooperative games, like the PBM above, stem from two sources. First, the indices cannot take strategic inter-institutional or procedural aspects of EU decision-making into account and, second, they do not explicitly consider players' preferences but rather attempt to model voting behaviour more

\footnotetext{
${ }^{9}$ It is often referred simply to as the Banzhaf index or measure (see, however, Felsenthal \& Machover (1998)).
} 
directly. The latter drawback is not necessarily severe in constitutional analysis. It can also be seen as a reason to support abstract cooperative approach but the former has to be taken more seriously even in constitutional analysis.

When there are more than one decision making institution involved with the decision making procedure or when one is investigating the interaction between several institutions classical power index approach faces problems as it assumes that players are voting or moving simultaneously, which is rarely, if ever, the case in decision making procedures. Consider a simple agenda setting game where we have an institution that makes a legislative proposal to a decision making body which either accepts or rejects the proposal. Simultaneous coalition based approach can only use the fact that all winning coalitions must contain the acceptance of the agenda setting institution plus a required majority in decision making institution. This approach, however, completely disregards the fact that the agenda setter moves first - decision making is procedural not simultaneous. Suppose for simplicity that the agenda setter is a single player and the passage of a proposal requires unanimous acceptance in the decision making body. Then the power index approach suggests that each player in the latter is as powerful as the former but it is not trivially true since the agenda setter moves first.

The criticism towards classical power indices above does not, however, mean that the core of power index approach, namely a player's marginal contribution to the outcome is useless. For this reason, we propose to extend above analysis from the simple coalition framework of a priori power measurement and the very basic voting game just considered to a more general framework. First, take a player's marginal contribution as the best available indicator of his potential or ability to make a difference, i. e. his a posteriori power. Second, if this is of normative interest or a necessity for lack of precise data, calculate a priori power as expected a posteriori power. Expectation can be with respect to several different aspects of a posteriori power such as actions, preferences, or procedure. This allows the (re-)foundation of a priori measures on a well-specified notion of a posteriori power. ${ }^{10}$ 
Crucially, impact is always relative to a what-if scenario. The shadow outcome is the group's decision which would have resulted if the player whose power is under consideration had chosen differently than he a posteriori did, e. g. if he had stayed out of coalition $S$ when he a posteriori belongs to it, or had ideal point 0 instead of 1 . While in simple games the difference between shadow outcome and actual outcome is either 0 or 1 , a richer decision framework allows for more finely graded a posteriori power.

To illustrate, let $\Lambda=\left(\lambda_{1}, \ldots, \lambda_{n}\right)$ be the collection of $n$ players' ideal policy positions in $R^{m}$ (an $m \times n$ matrix having as columns the $\lambda_{i}$-vectors representing individual players' ideal points). In a policy space $X \subseteq R^{m}$, the opportunities even for only marginal changes of preference are manifold. A given ideal point $\lambda_{i}$ can locally be shifted to $\lambda_{i}+h$ where $h$ is an arbitrary vector in $R^{m}$ with small norm. Which tremble directions it is reasonable to consider in applications will depend. Multiples of the vector $(1,1, \ldots, 1) \in R^{m}$ seem reasonable if the $m$ policy dimensions are independent of each other.

In any case, if the vector $h$ that describes the direction of preference trembles has norm $\|h\|$ and so $\alpha=\left(\alpha_{1}, \ldots, \alpha_{m}\right)=\frac{h}{\|h\|}$ is its normalized version, one can define

$$
D_{i}(\Lambda):=\lim _{t \rightarrow 0} \frac{x^{*}\left(\lambda_{i}+t \alpha, \lambda_{-i}\right)-x^{*}\left(\lambda_{i}, \lambda_{-i}\right)}{t}=\frac{\partial_{\alpha} x^{*}\left(\lambda_{i}, \lambda_{-i}\right)}{\partial \lambda_{i}}
$$

as a reasonable measure of player $i$ 's a posteriori power provided that above limit exists. This is simply the directional derivative of the equilibrium outcome in the direction $h$ or $\alpha$.

Having selected a meaningful measure of ex post power, it is straightforward to define a meaningful ex ante measure. It has to be based on explicit informational assumptions concerning players' preferences or - if one does not want to assume preference-driven behavior - actions. Denoting by $\tilde{\xi}$ the random state of the world as given either by preferences (and status quo) or players' actions, and by $P$ its distribution,

$$
\mu_{i}^{\Gamma}:=\int D_{i}(\tilde{\xi}) d P
$$

\footnotetext{
${ }^{10}$ Another way to approach power is spatial voting is to use the inverse of the distance between actors' ideal policies and the outcome (see Steunenberg et al. 1999 and Napel and Widgrén 2002 for discussion).
} 


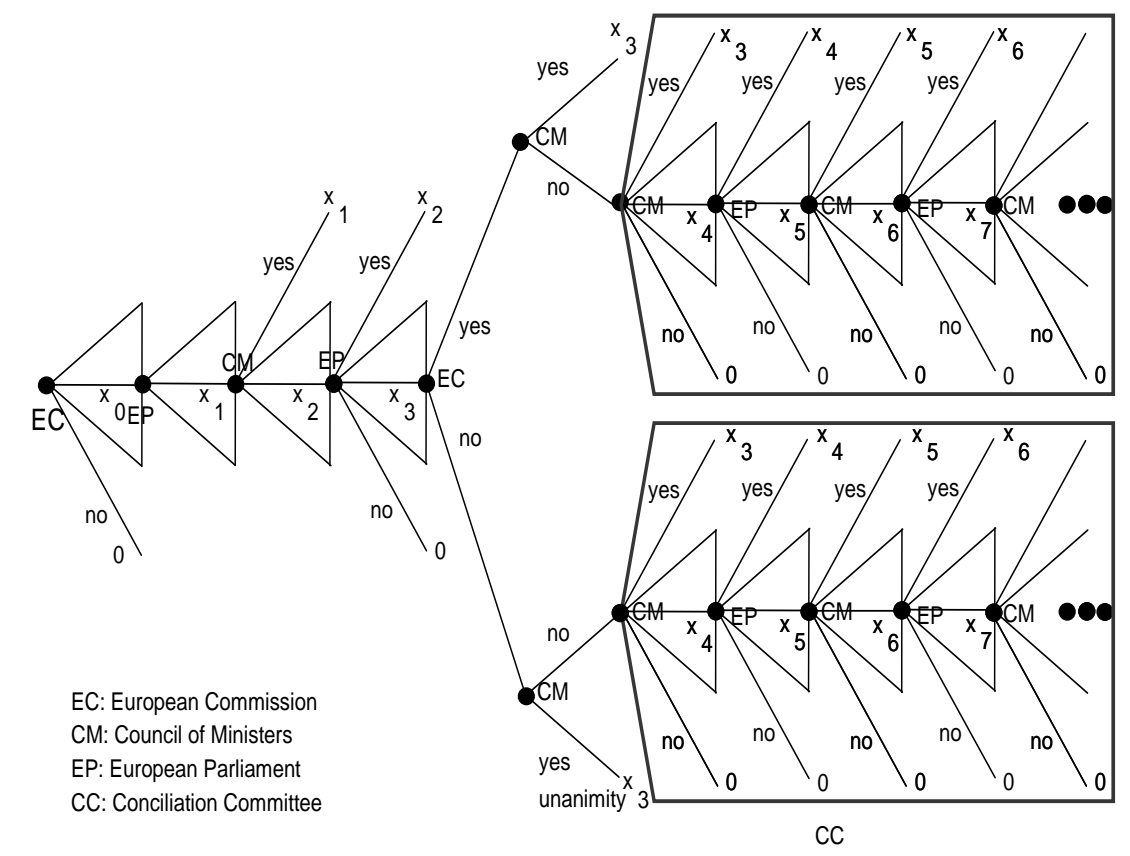

Figure 2: Co-decision procedure

is the ex ante power index based on ex post measure $D_{i}(\cdot)$ and decision procedure $\Gamma$.

\section{Investigating the institutional structure of the EU}

The EU has three main decision-making bodies: the Commission, the Council and the European Parliament (EP) and two main decision-making procedures: consultation and co-decision procedure (see figure 2 for the sequence of moves in co-decision procedure). The most fundamental difference between the procedures is that the former is emphasizes inter-governmental approach whereas the latter has more supra-national and federalist elements. In consultation procedure, the Commission proposes and the Council decides. Unanimous Council can amend the Commission proposal. The Commission can also decide to not to propose and then the legislative status quo prevails. The Commission, thus exerts agenda-setting power and gate-keeping power and the Council decision-making power. In consultation procedure, the EP can only express its opinion on a proposal but this does not bind the Council or the Commission. Co-decision procedure is more complicated. The 
main difference to consultation procedure is that co-decision gives significant powers to the EP. Figure 2 gives a detailed description of the procedure. The Commission submits a proposal to the EP to its first reading. The EP can accept a proposal or amend it. In each case the proposal, the original or amended, is submitted to the Council where it can be accepted or further amended. The former leads to outcome $x_{1}$ and the latter to a proposal $x_{2}$. That can be then accepted, amended or rejected by the EP. This stage of the procedure gives the EP some agenda setting powers. A proposal $x_{3}$ is then studied by the Commission. It can reject or accept the proposal $x_{3}$ but not to amend it any more. The next mover is the Council that can accept $x_{3}$ by qualified majority in the case of Commission acceptance and unanimously in the case of Commission rejection. Note that, in fact, the Commission view does not bind the Council at all since by over-ruling it the Council can start conciliation with the EP. In practise this means that EP and the Council can together amend the Commission proposals and, as this does not require unanimous acceptance in either of these bodies, co-decision, in fact, seems to restrict the Commission powers significantly.

The Conciliation Committee is chaired by the Vice-President of the European Parliament and a representative of the member state that is holding presidency in the Council. Before the Committee meets the member state that is holding presidency has, however, a leading role and also gate-keeping power. To put this into a more general perspective one alternative way to model decision-making in the Conciliation Committee is a simple agenda-setting model where the Executive makes the initiative. The Executive could be the member state that is holding Presidency in the Council or a chosen President. The former scenario emphasizes inter-governmental approach as it gives agenda-setting power to each government on rotating basis whereas the latter scenario gives the agenda-setting power to a separate supranational institution. Let us refer to these models more generally as the Executive model. The third alternative is to interpret the procedure as (alternating offers) bargaining game between the EP and the Council (for details see Napel \& Widgrén 2003).

As mentioned above, consultation procedure relies purely on inter-governmental ap- 
proach. That is why it can be best applied in decision-making on policy domains that belong to enhanced co-operation projects. The degree of supranationalism can be measured by the Commission's power relative to the Council. Within the Council OPOV principle should hold.

Co-decision procedure can be interpreted as federal approach requiring then that both OPOV and USC principles hold and the latter guarantees equal weights to the EP and the Council. If the constitution gives higher weight to the Council co-decision moves towards inter-governmental approach.

Table 1 shows the effects of Nice reforms on majority threshold before and after the enlargement and the effects of enlargement with under pre-Nice and post-Nice quota. Table 2 gives the corresponding effects in co-decision procedure. 11 The total effect can be computed either by by taking the effect of enlargement under the old threshold and then the threshold effect or by taking the effect of the change in threshold and then the effect of the enlargement under the new threshold. The total effects are shown on the two rightmost columns of the third row. As before EP refers to the European Parliament, $\mathrm{CM}$ to the Council and EC to the Commission. In both tables columns 2 and 3 give the pre-enlargement figures, columns 4 and 5 post-enlargement figures and columns 6 and 7 the differences.

Table 1 shows that both the Council and the Commission gained somewhat in consultation procedure as a result of Nice reforms. More generally, this procedure is a simple intergovernmental almost a take-it-or-leave-it offer agenda-setting game. With an exception of very high quotas membership seems to benefit the agenda-setter, i.e. the Commission, whereas the legislature, i.e. the Council, seems to loose power. To restore the balance between the two enlargements give Member States incentives to increase the vote threshold, like it was decided in Nice. It is worth noting though that each individual Member State loses power due to an enlargement since the number of Member States in the Council

\footnotetext{
${ }^{11}$ Here we disregard the effects of the changes in inter-Council distribution of power. According to the earlier results the power distribution within the Council does not have a significant effect on interinstitutional distribution of power at the aggregate level.
} 
Table 1: The effects of Nice reforms and enlargement on strategic inter-institutional power in consultation procedure

\begin{tabular}{lcccccc}
\hline \hline & \multicolumn{2}{c}{ Current EU } & \multicolumn{2}{c}{ Enlarged EU } & \multicolumn{2}{c}{ Difference } \\
\hline & $\mathrm{CM}$ & $\mathrm{EC}$ & $\mathrm{CM}(\mathrm{E})$ & $\mathrm{EC}(\mathrm{E})$ & $\mathrm{DCM}$ & $\mathrm{DEC}$ \\
\hline $\mathrm{Q}=71$ per cent & 0.813 & 0.531 & 0.744 & 0.592 & -0.069 & 0.061 \\
$\mathrm{Q}=74$ per cent & 0.922 & 0.477 & 0.831 & 0.549 & -0.092 & 0.072 \\
Difference & 0.109 & -0.054 & 0.086 & -0.043 & 0.017 & 0.018 \\
\hline \hline
\end{tabular}

Table 2: The effects of Nice reforms and enlargement on strategic inter-institutional power in co-decision procedure

\begin{tabular}{lcccccc}
\hline \hline & \multicolumn{2}{c}{ Current EU } & \multicolumn{2}{c}{ Enlarged EU } & \multicolumn{2}{c}{ Difference } \\
\hline & $\mathrm{EP}$ & $\mathrm{CM}$ & $\mathrm{EP}(\mathrm{E})$ & $\mathrm{CM}(\mathrm{E})$ & $\mathrm{DEP}$ & $\mathrm{DCM}$ \\
\hline $\mathrm{Q}=71$ per cent & 0.178 & 0.658 & 0.173 & 0.668 & -0.005 & 0.010 \\
$\mathrm{Q}=74$ per cent & 0.162 & 0.731 & 0.162 & 0.727 & 0.000 & -0.004 \\
Difference & -0.016 & 0.073 & -0.011 & 0.059 & -0.016 & 0.069 \\
\hline \hline
\end{tabular}




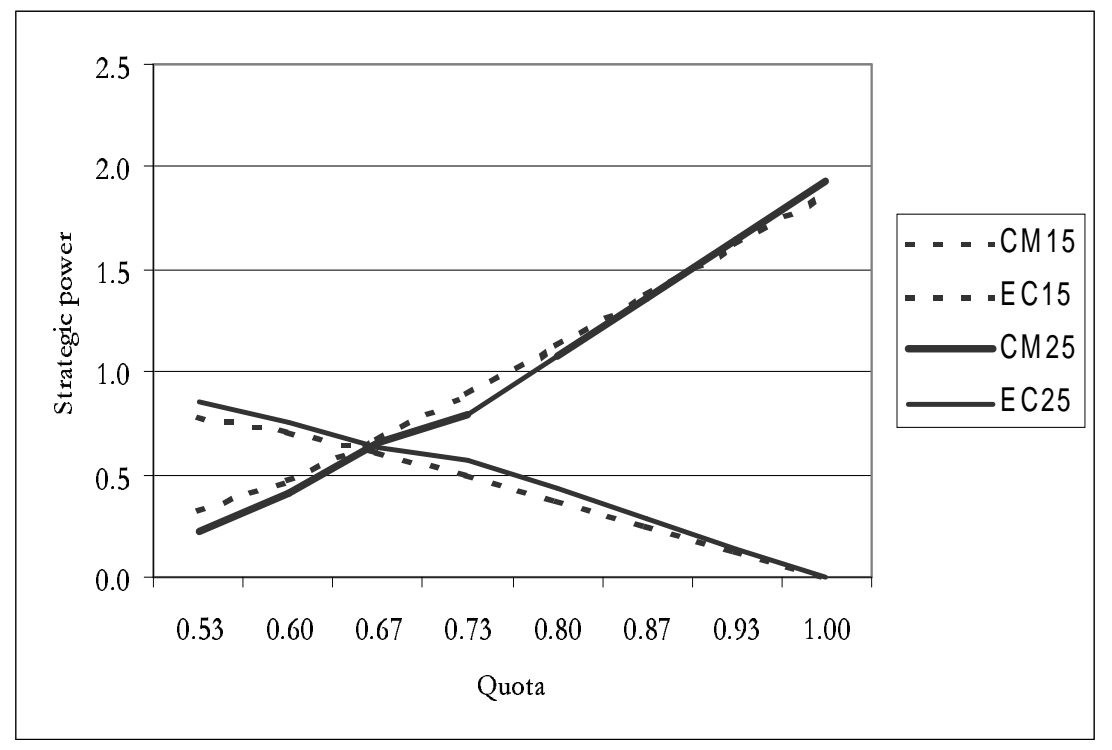

Figure 3: Strategic Power in Consultation Procedure

increases.

In consultation procedure, the threshold in the Council that balances power between the Commission and the Council is 67 per cent in the EU15 and remains the same in the EU27. Figure 3 demonstrates this more generally. It shows the effects of enlargement on strategic power measures of the Council that in increasing with the quota and the Commission that is decreasing with the quota used in the Council. The figure shows that the effect of the enlargement is almost monotonic with the quota. Even at high quotas the Council loses power and the Commission gains. As an exception, at unanimity rule, the Council gains and there are no significant effects for the Commission. From the viewpoint of interinstitutional power this makes unanimity rule stable as there are no strong incentives to deviate from it when the membership expands. Figure 3 suggests that two-thirds majority is another stable candidate.

In the EU, consultation procedure was the only legislative procedure till 1986 and unanimity rule was the only voting rule till 1966. After that Luxembourg compromise made it, however, possible to ask for unanimity on the grounds of national interests even when majority decision was possible. Qualified majority voting was mainly plugged in by 


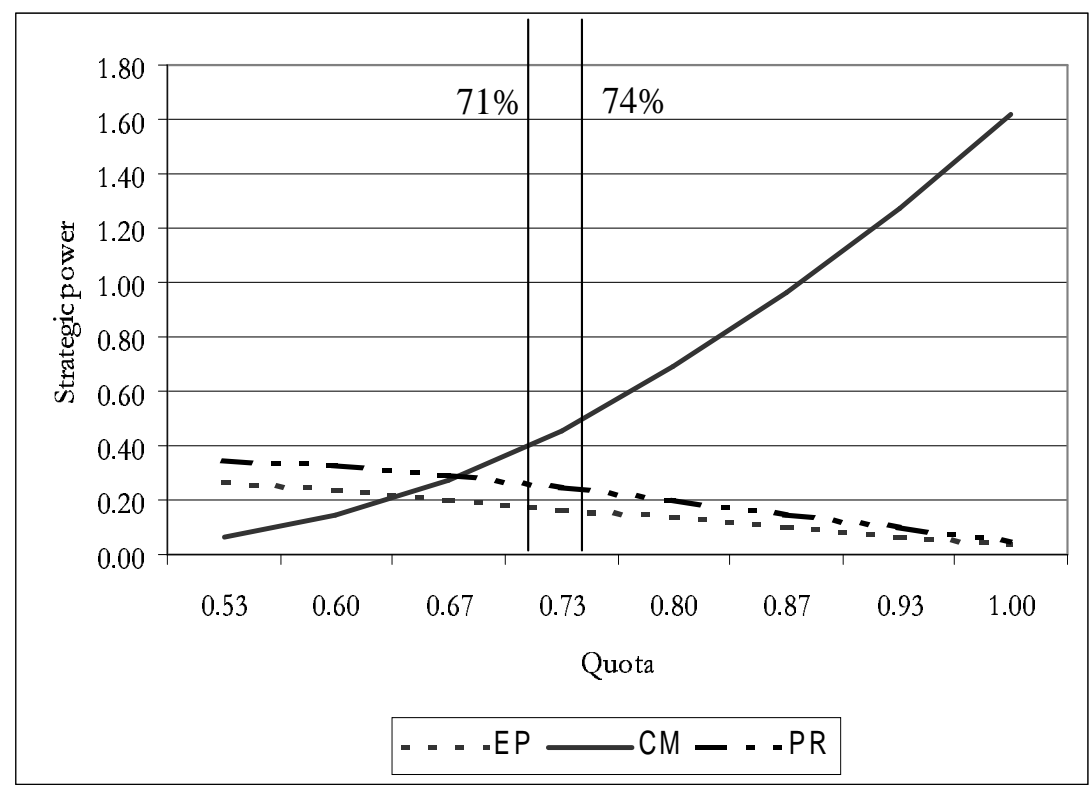

Figure 4: Strategic Power in Co-decision Procedure

introducing a new procedure to serve the Single Market programme. Still today unanimity is more often applied in consultation procedure than in co-decision procedure.

If unanimity rule is, in terms of inter-institutional balance of power, so stable one may wonder what explains the deviation from it in the EU since the late-1980s. The explanation may follow from the fact that it is stable only from the viewpoint of interinstitutional balance of power but not on the viewpoint of intra-institutional distribution of power. In relative terms, the big countries lose more than the small countries as the membership expands and unanimity rule is applied. This question is analyzed more in detail in section 5 below.

In co-decision procedure, the magnitude of the effects is smaller than in consultation procedure. Especially the impact of the enlargement is practically zero (see table 2). The main difference between the procedures is that, in consultation procedure, the equilibrium outcome is determined by the policy positions of (the median voter in) the Commission and the pivotal player in the Council the former being the legislative initiator and, in codecision procedure, the policy positions of the pivotal player in the Council and the median voter in the EP both being decision-makers in the Conciliation Committee. In both cases 
the source of Council gains is the fact that it uses qualified majority threshold whereas the Commission and the EP use absolute majority. The increase of the quota from 71 per cent to 74 per cent benefitted the Council as can be seen in table 2 .

Figures 4 and 5 give the inter-institutional balance of power in co-decision procedure in EU-27 and the impact of the enlargement on it when the procedure is modelled as the Executive model as discussed above. Figure 4 shows that the Council exerts more power than the EP as far as the quota is higher than 62 per cent. The Executive is more powerful than the EP regardless of the quota. The division of power between the Executive and the Council is equal at two-thirds majority rule. This, in fact, corresponds with consultation procedure where the Commission is the Executive, which is intuitively plausible.

Using the current vote threshold in the Council, co-decision procedure is very neutral to the enlargement. There are no substantial changes in inter-institutional power. For the quotas higher than this the enlargement gives increasing power gains for the Council whereas effects for the EP and the member state that is holding presidency. In sum, it seems that the increase in majority quota that was decided in Nice can be explained by the balance of power in consultation procedure. In co-decision procedure, the old and the new threshold fall into stable region. It is worth noting, however, that in both procedures enlargements tend to give incentives for member states to increase the quota.

The Executive model of the co-decision procedure can be seen as a combination of two "sub-games". If the Executive has agenda setting power in the Conciliation Committee the relationship between the Executive and the Council is like the one in consultation procedure. If this is not the case conciliation committee can be interpreted as an alternating offers bargaining between the median voter in the EP and the pivotal player in the Council.

In weak Executive scenario, which corresponds rather well with the current co-decision procedure, there is a clear first mover advantage in the Conciliation Committee. In relative terms, the advantage works in favour of the Council. If it is the first mover in the Conciliation Committee it is more powerful than the EP regardless of the quota. If the EP offers first the Council is more powerful if the quota exceeds two-thirds, like in consultation procedure between the Commission and the Council. The main reason for this asymmetry 


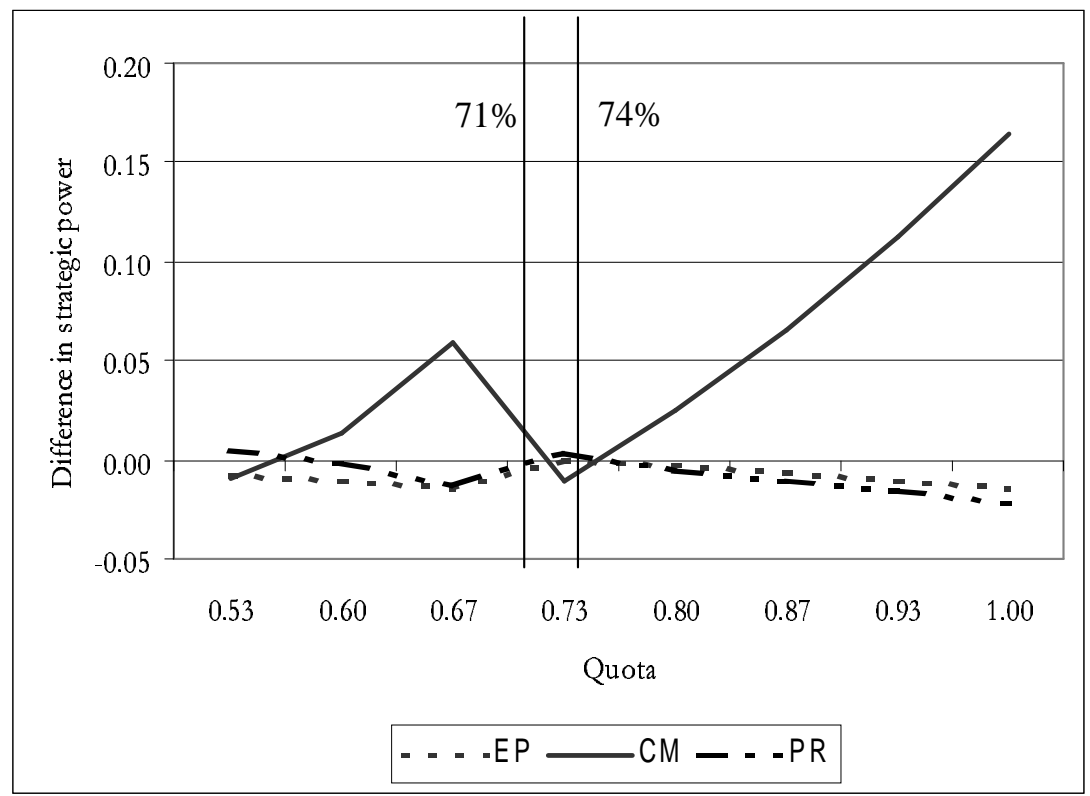

Figure 5: The Effect of Enlargement on Strategic Power in Co-decision Procedure

is the fact that the ideal policy position of the pivotal player in the Council is likely to be more biased towards the legislative status quo than position of the median voter in the EP. This works like patience in normal bargaining set-up. ${ }^{12}$

In powerful Executive scenario, which is modelled above, the distribution of power between the Council and the EP is neutral to the enlargement. If the Executive is the rotating Council Presidency the Council is more powerful than the EP. This roughly corresponds with the case where the Council is the first mover in alternating offers bargaining. The total influence of the Council is a vertical sum of CM and PR curves in figure 4.

If the Executive is a separate institution there are two alternatives. First, there is the so-called double-hat idea where an elected Commission President acts as the President of the Council as well and, second, there is a proposal that Presidents of the Commission and the Council are two different institutions the latter being elected for instance by a qualified majority of the Council. Figure 4 also captures the impact of these proposals in co-decision. If the Commission President becomes the head of the Council PR-curve

\footnotetext{
${ }^{12}$ See Napel \& Widgrén (2003), for details.
} 
gives the power of the Commission in the procedure. It would shift some powers from the Council to the Commission but still using the current quota in the Council would maintain its role as the most powerful actor. If a separate President is chosen the PR-curve gives his/her power and the Commission is left out with its gate-keeping power. That has an important and potentially far-reaching implication, namely co-decision becomes inefficient, like it is the case with rotating Presidency as well.

\section{Inefficiency in co-decision}

An often used method to assess decision-making efficiency refers to an institutions capability to act or make decisions. ${ }^{13}$ The main drawback of the efficacy measure like this is its lack of strategic aspects. An abstract measure of an institution's capability to act simply computes the share of majority coalitions of all coalitions. Taking strategic aspects into account might give a different and more procedure related picture on the sources of inefficiency. For simplicity let us assume that the policy space is normalized to unit interval and the actors have ideal points that are assumed to be uniformly distributed on the interval. As the status quo is normalized to zero this means that all stakeholders are on the same side of the status quo and there are always gains from trade. There, thus, always exists a proposal that makes all players better-off than the status quo.

A common feature in consultation and co-decision procedures is that the Commission proposal can be amended and the amended proposal can then be accepted without the Commission's consent. In consultation procedure, unanimous Council can do that and, in co-decision procedure, the Conciliation Committee. This weakens the Commission as an executive and also makes the procedures inefficient. Since the Commission exerts gatekeeping power it may decide to not to make a proposal if it foresees that the outcome would be worse than the legislative reference point, i.e. status quo. That creates status quo bias and hence inefficiency since not all gains from trade are materialized. Note that

\footnotetext{
${ }^{13}$ For applications regarding the eastern enlargement see e.g. Baldwin et al. 2000, 2001 and the 1995 enlargement Widgrén 1993, 1995.
} 


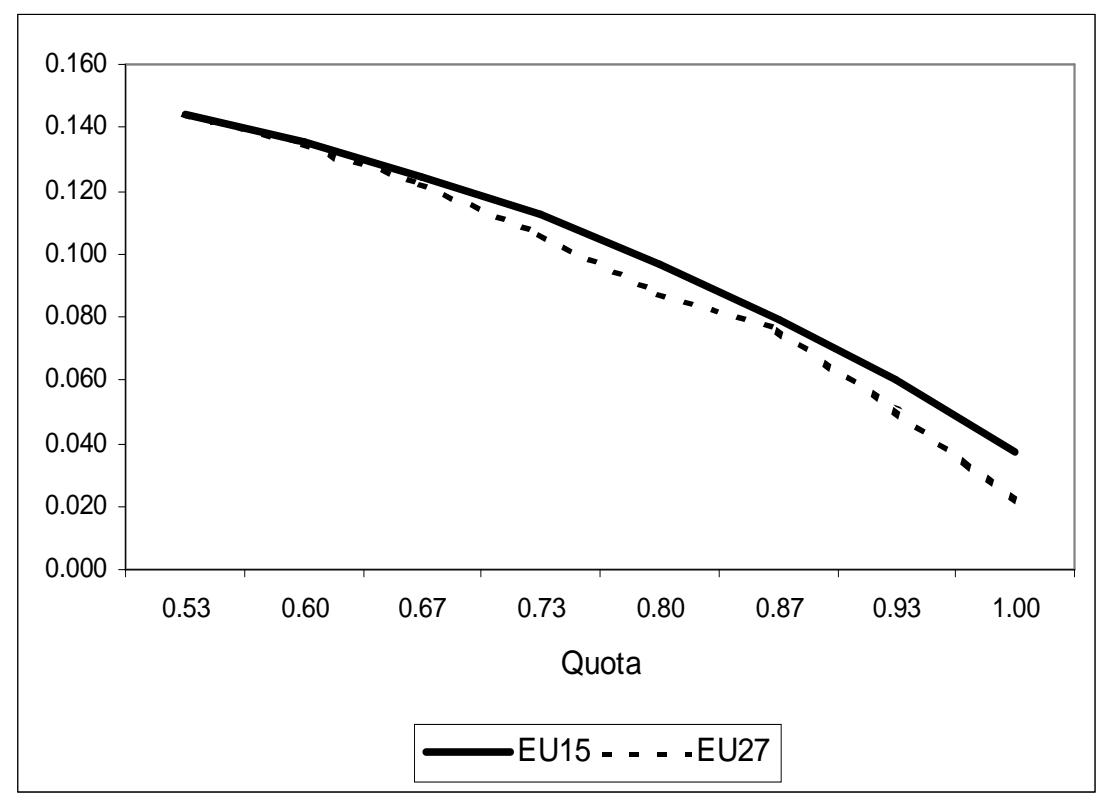

Figure 6: Status Quo Bias in Co-decision Procedure

there might also exist gains from trade in the sense that all actors prefer less integration or more decentralization. Status quo bias might then create centralization bias.

Figure 6 demonstrates this. It shows the probabilities of status quo bias, i.e. percentage of issues where the Commission has incentives to use its gate-keeping power in legislative equilibrium. The figure gives the probabilities before and after enlargement as the quota in the Council is let to vary.

The conclusions that can be drawn from figure 6 are quite opposite to those based on passage probabilities. First, increasing the quota in the Council decreases inefficiency and, second, enlargement has practically no effect at all. The first phenomenon can be explained by the fact that a higher threshold decreases efficacy in the Conciliation Committee. That makes it less likely that the Commission is willing to use its gate-keeping power. The outcome in the Conciliation Committee is then biased towards the status quo due to the quota used in the Council. The price of improving efficiency is deteriorating efficacy, which might limit the scope of EU decision-making superfluously. Using the current threshold gives the probability of status quo bias of more than one-tenth, which is substantial. Theoretically, 
every tenth decision that would have benefitted all is not taken. ${ }^{14}$

One important difference between co-decision and consultation procedure is that in the former the Council and the EP use the same quota in the conciliation committee as when they decide on Commission proposals. In consultation procedure amendments require a higher quota for their passage than Commission proposals. In co-decision procedure similar differentiation with vote thresholds in conciliation committee and on Commission proposals would reduce status quo bias in gate-keeping sense without necesarily deteriorating efficacy in passage probability sense. It is worth noting, however, that this solution only reduces inefficiency and is not able to remove it completely. ${ }^{15}$ That would also give some powers to the Commission in the procedure. Another even more straightforward solution could be to make the Commission politically accountable but that would not remove the inefficiency property from the procedure per se. A third alternative would be to abolish the Commission's monopoly as an initiator and to share it with another supranational institution, namely the EP.

\section{Equal representation of EU citizens}

In the inter-governmental conference 2000, the Commission proposed and advocated the so-called simple dual (SD) majority voting rule in the Council. SD rule reflects the Union of nations and union of citizens principle since when it is applied a legislative proposal needs the acceptance of majority of member states and majority of EU citizens to pass. it is worth noting that SD rule is not weighted voting. Member states governments do not have voting weights but the rule itself determines whether a proposal passes and the

\footnotetext{
${ }^{14}$ In consultation procedure, status quo bias does not practically exist in the above-mentioned sense. Unanimous Council can amend Commission proposals but the likelihood of amending them in a way that leads the Commission to use its gate-keeping power is very small. In the EU15 the probability of status quo bias in consultation procedure is $1.9 \cdot 10^{-6}$ and in the EU27 even smaller.

${ }^{15} \mathrm{~A}$ solution where conciliation requires unanimous consent of the EP and the Council would in practise remove it but would decrease efficacy dramatically.
} 
distribution of power among member states. ${ }^{16}$

The Commission proposal was meant to the Council. More generally SD rule is typical for federal states. For instance in the U.S. the majority of states part of the definition is reflected by the decision-making rules in the Senate and the majority of citizens part in the House of Representatives. If both chambers are equally powerful, like in the U.S., and the assessment is only interested in national distribution of power the analysis gives the same conclusions in one and two-chamber decision-making. In the context of the EU co-decision among the Council and the Parliament has similarities with a normal federal system with exception that the Council and the Parliament use different quotas.

One person one vote (OPOV) principle is a cornerstone in designing democratic institutions and fair allocation of power in a federation or two-tier decision-making in general. ${ }^{17}$ In big states citizens have less power in choosing their national government than citizens in small states. This requires that the big states are compensated in the Council voting weights. The right compensation to ensures OPOV principle is the well known square-root rule due to Penrose (1946). Applied to the EU Council, fair power of countries should be determined by their square-root shares of population. Hence fair power of country $i$ can be written

$$
\beta^{*}=\frac{\sqrt{m_{i}}}{\sum_{j=1}^{n} \sqrt{m_{j}}}
$$

where $m_{i}$ denotes the population of country $i$ and $\beta^{*}$ the fair (Banzhaf) index of power.

Table 3 gives the summary of differences between normalized Banzhaf indices when two alternative dual majorities are used in the Council of the EU15 and EU27. The difference that we use is the sum of squares of the differences between the actual Banzhaf indices and the fair ones. In the table, D50 refers to simple dual majority, i.e. absolute majority of states and citizens, D62 refers to absolute majority of states and 62 per cent

\footnotetext{
${ }^{16}$ Simple dual majority can, however, be interpreted as a weighted voting with an additional safety-net that guarantees support from an absolute majority of member states.

${ }^{17}$ For earlier analysis on the EU see Laruelle and Widgrén 1998.
} 
Table 3: The sum of squares of the differences between the BI and square-root rule, $\cdot 10^{-3}$.

\begin{tabular}{lll}
\hline \hline rule & EU15 & EU27 \\
D50 & 2.166 & 2.037 \\
D62 & 3.588 & 2.690 \\
D74 & 5.805 & 6.234 \\
DS50 & 6.100 & 4.668 \\
DS62 & 0.100 & 0.057 \\
DS74 & 0.252 & 0.051 \\
Nice & 0.749 & 5.494 \\
\hline \hline
\end{tabular}

majority of citizens ${ }^{18}$ D74 to absolute majority of states and 74 per cent majority of citizens respectively. The alternatives SD50, SD62 and SD74 refer to similar dual majorities where and absolute majority of member states and 50 per cent, 62 per cent and 74 per cent majority of member states' square-rooted population is needed to pass legislation. Let us refer to these rules to as square-root dual majorities. The last rows of each table give the results regarding the Nice reform.

The performance of the three categories suggests, not surprisingly that square-root weights give power distribution that is very close to the square-root rule. That is a common feature of classical power indices. When the number of players increases power measures converge to voting weights if the variance of weights is relatively small. In the category of square-root dual majorities the performance is almost as good with an exception of the case where an absolute majority of square-rooted population is needed (SD50), which in terms of equal representation of EU citizens turns out to be the worst voting rule. In the category of dual majorities, simple dual majority performs the best.

Figure 7 confirms and generalizes the results in table 3 . The figure shows the sums of

\footnotetext{
${ }^{18}$ The choice of 62 per cent is inspired by the Nice reform, which defines the voting rules in the Council as a mixture of voting weights and and D62 rule.
} 


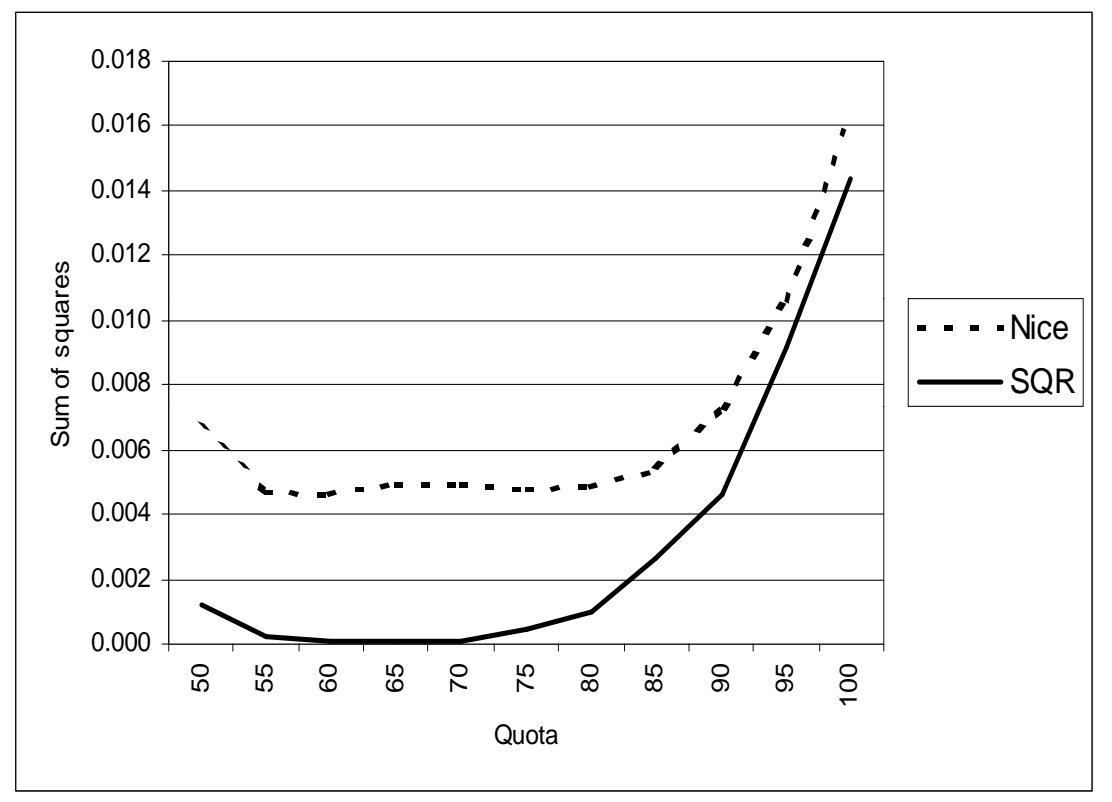

Figure 7: The difference between OPOV principle and the Nice rules and square-root dual majorities

squares of the differences between the fair power indices based on OPOV principle and the actual ones when the Nice weights and square-root dual majorities are used. It is common for both models that there is a wide range of majority rules that are equally good. For the Nice weights there are practically no differences in the range of thresholds between 55 and 80 per cent. The performance of square-root dual majorities remain unchanged between 55 and 70 per cent quotas. Note however that square-root dual majorities perform better that the Nice weights at their best can do on the range between 50 and 90 per cent quotas. Most important conclusion that can be drawn from table 3 and figure 7 is that, to fulfil the OPOV principle, square-root dual majorities seem to fit the best to the Council. Moreover, the rule is as transparent as simple dual majority proposed by the Commission, which would serve as the second best solution here.

Figure 7 also explains why unanimity rule is not stable in the Council although in both procedures there is a tendency towards it. The difference between OPOV principle and the actual power increases rapidly when the quota is high enough. This is unfavourable to big countries creating deviating forces. Interestingly, in both procedures there are other stable 
majority rules than the unanimity rule and they belong to the range where the difference to OPOV principle is minimized.

\section{Conclusions}

In this paper, we have studied EU decision-making procedures and voting rules. The particular focus of the analysis has been on their neutrality to membership. The paper has assessed inter-institutional power in the two main decision-making procedures of the EU, decision-making efficacy and efficiency and national distribution of power and the impact of expanding membership in all these. The objective of the paper has been to study how well some general constitutional principles can be used to design decision-making in the EU and how neutral decision-making rules that are based on such principles.

The paper demonstrates that the inter-institutional power in EU procedures is relatively neutral to expanding (or decreasing) membership. Especially this holds for co-decision procedure. In both procedures there is a tendency towards unanimity rule if the quota is decided by Member States governments but both procedures have stable majority rules

The extreme alternatives of the nature of the EU are purely inter-governmental Union and USC principle. The former suggests strong Council and no or very minor role for the Commission and the EP. The latter suggests co-decision between the EP and the Council and relatively strong but accountable Commission. If the current rules are used in consultation procedure, the Council is the most powerful actor. Despite to its role as the initiator the Commission exerts less power. The difference is not very big though. Consultation procedure is not, therefore, purely inter-governmental procedure but as it fails to meet the USC principle it should not be applied in policy domains that belong to the Union competence but rather in the policy domains that are organized under enhanced cooperation. The results suggest that two-thirds majority balances the power between the Commission and the Council.

Co-decision procedure fits better to the USC principle. The paper models the procedure by giving a strong official role to the Executive that can be the Member State that is holding 
presidency or an elected President. The former model makes the Council the most powerful actor and makes it impossible to obey the USC principle. The role of the EP is weaker and there are no majority rules that make the EP equal partner to the Council.

Another feature of the procedure is the Commission role, which has been diminished to gate-keeping since the Council and the EP use the same threshold in the Conciliation Committee and when they decide on Commission proposals. That makes the procedure inefficient. The likelihood of inefficiency is neutral to membership though.

A solution candidate for inefficiency problem is to apply higher thresholds in the Conciliation Committee than when deciding on Commission proposals. Another solution could be to make the Commission politically accountable to the EP and the Council, which would diminish harmful gate-keeping. These solutions would not remove the problem completely though.

An alternative approach would be to divide the right to initiate between the Commission and the EP. As the EP is a part of Conciliation Committee this would make the procedure efficient. It would also intensify competition between the proposals. Inefficiency problem can also be solved by introducing a strong Executive. It is worth noting, however, that this requires the so-called double-hat Presidency where the President of the Commission is the President of the Council as well.

Distribution of national power is another important aspect of EU institutions. Intrainstitutional distribution of power does not have significant impact on inter-institutional distribution of power but enlargements have effects on intra-institutional power and the performance of USC and OPOV principles. That is why this question is analyzed separately. There seems to be a trade-off between OPOV and USC principles as the constitutional base for decision-making rules in the EU. Simple dual majority rule that takes the USC rule most literally does not perform very well in terms of citizens' equal representation. It would be an improvement to the current weighting though. The so-called square-root dual majorities are as transparent as (simple) dual majorities and carry out power distribution that are practically identical with the fair one. 


\section{References}

Baldwin, Richard, Erik Berglöf, Francesco Giavazzi, and Mika Widgrén (2000) "The EU Reforms for Tomorrow's Europe." CEPR Discussion Paper 2623.

Baldwin, Richard, Erik Berglöf, Francesco Giavazzi, and Mika Widgrén (2001) "Nice Try: Should the Treaty of Nice Be Ratified?" Monitoring European Integration 11. London: Centre for Economic Policy Research.

Crombez, Cristophe (1996) "Legislative Procedures in the European Community." British Journal of Political Science 26: 199-228.

Crombez, Cristophe (1997) "The Co-Decision Procedure in the European Union." Legislative Studies Quarterly 22: 97-119.

Felsenthal, Dan, and Moshé Machover (1998) The Measurement of Voting Power: Theory and Practice, Problems and Paradoxes. Cheltenham: Edward Elgar.

Felsenthal, Dan, and Moshé Machover (2001a) "Myths and Meanings of Voting Power." Journal of Theoretical Politics 13: 81-7.

Felsenthal, Dan, and Moshé Machover (2001b) "The Treaty of Nice and Qualified Majority Voting." Social Choice and Welfare 18: 431-64.

Garrett, Geoffrey, and George Tsebelis (1999a) "Why Resist the Temptation to Apply Power Indices to the EU." Journal of Theoretical Politics 11: 291-308.

Garrett, Geoffrey, and George Tsebelis (1999b) "More Reasons to Resist the Temptation to Apply Power Indices to the EU." Journal of Theoretical Politics 11: 331-8.

Garrett, Geoffrey, and George Tsebelis (2001) "Even More Reasons to Resist the Temptation to Apply Power Indices to the EU." Journal of Theoretical Politics 13: 99-105.

Holler, Manfred, and Mika Widgrén (1999) "Why Power Indices for Assessing EU DecisionMaking?" Journal of Theoretical Politics 11: 321-30.

Kirman, Alan, and Mika Widgrén (1995) "European Economic Decision-Making Policy: Progress or Paralysis?" Economic Policy 21: 421-60. 
Laruelle, Annick, and Mika Widgrén (1998) "Is the Allocation of Power Among EU States Fair?" Public Choice 94: 317-39.

Laruelle, Annick, and Valenciano, Federico (2002) "Assessment of Voting Situations: The Probabilistic Foundations." Discussion Paper No 26/2002, Departamento de Economía Aplicada IV, Basque Country University, Bilbao, Spain.

Leech, Dennis (2002) "Designing the Voting System for the Council of Ministers of the European Union." Forthcoming in Public Choice.

Moser, Peter (1996). "The European Parliament as a Conditional Agenda Setter: What Are the Conditions? A Critique of Garrett and Tsebelis" (1994) American Political Science Review 90: $834-8$.

Moser, Peter (1997) "A Theory of the Conditional Influence of the European Parliament in the Cooperation Procedure." Public Choice 91: 333-50.

Napel, Stefan, and Mika Widgrén (2001) "Inferior Players in Simple Games." International Journal of Game Theory 30: 209-20.

Napel and Widgrén (2002) "Strategic Power Revisited." CESifo Working Paper No. 736, Munich.

Napel, Stefan, and Mika Widgrén (2003) "Modelling Codecision Bargaining." Mimeo.

Nurmi, Hannu (1998) Rational Behavior and the Design of Institutions. Edward Elgar, Cheltenham.

Penrose, Lionel (1946) "The Elementary Statistics of Majority Voting." Journal of the Royal Statistical Society 109: 53-7.

Steunenberg, Bernard (1994) "Decision-Making under Different Institutional Arrangements: Legislation by the European Community." Journal of Theoretical and Institutional Economics 150: 642-69.

Steunenberg, Bernard, Dieter Schmidtchen, and Christian Koboldt (1999) "Strategic Power in the European Union: Evaluating the Distribution of Power in Policy Games." Journal of Theoretical Politics 11: 339-66.

Tsebelis, George (1994) "The European Parliament as a Conditional Agenda Setter." American Political Science Review 88: 128-42. 
Tsebelis, George (1996) "More on the European Parliament as a Conditional Agenda Setter: Response to Moser." American Political Science Review 90: 839-44.

Tsebelis, George, and Geoffrey Garrett (1997) "Why Power Indices Cannot Explain DecisionMaking in the European Union." In Constitutional Law and Economics of the European Union, ed. Dieter Schmidtchen and Robert Cooter. Cheltenham: Edward Elgar.

Widgrén, Mika (1994) "Voting Power in the EU and the Consequences of Two Different Enlargements." European Economic Review 38: 1153-70.

Widgrén, Mika, and Stefan Napel (2002) "The Power of a Spatially Inferior Player." Homo Oeconomicus 19: 327-43. 


\title{
CESifo Working Paper Series
}

\author{
(for full list see www.cesifo.de)
}

837 Carola Grün and Stephan Klasen, Growth, Income Distribution, and Well-Being: Comparisons across Space and Time, January 2003

838 Robert S. Chirinko and Ulf von Kalckreuth, On the German Monetary Transmission Mechanism: Interest Rate and Credit Channels for Investment Spending, January 2003

839 Sascha O. Becker, Andrea Ichino, and Giovanni Peri, How Large is the "Brain Drain" from Italy?", January 2003

840 Albert Berry and John Serieux, All About the Giants: Probing the Influences on Growth and Income Inequality at the End of the $20^{\text {th }}$ Century, January 2003

841 Robert Fenge and Martin Werding, Ageing and the Tax Implied in Public Pension Schemes: Simulations for Selected OECD Countries, January 2003

842 Robert Fenge and Martin Werding, Ageing and Fiscal Imbalances Across Generations: Concepts of Measurement, January 2003

843 Giovanni Andrea Cornia, The Impact of Liberalisation and Globalisation on Income Inequality in Developing and Transitional Economies, January 2003

844 Peter Fredriksson and Per Johansson, Program Evaluation and Random Program Starts, January 2003

845 Bernd Hayo and Matthias Wrede, Fiscal Equalisation: Principles and an Application to the European Union, January 2003

846 Syed M. Ahsan and Jaideep Oberoi, Inequality, Well-being and Institutions in Latin America and the Caribbean, January 2003

847 Chang Woon Nam and Doina Maria Radulescu, The Role of Tax Depreciation for Investment Decisions: A Comparison of European Transition Countries, January 2003

848 V. Bhaskar and Steinar Holden, Wage Differentiation via Subsidised General Training, January 2003

849 Paloma Lopez-Garcia, Labour Market Performance and Start-up Costs: OECD Evidence, January 2003

850 Christian Keuschnigg and Soren Bo Nielsen, Public Policy for Start-up Entrepreneurship with Venture Capital and Bank Finance, January 2003

851 Yin-Wong Cheung, Menzie D. Chinn, and Eiji Fujii, China, Hong Kong, and Taiwan: A Quantitative Assessment of Real and Financial Integration, January 2003 
852 Gregory D. Hess, The Economic Welfare Cost of Conflict: An Empirical Assessment, February 2003

853 Douglas J. Cumming and Jeffrey G. MacIntosh, Comparative Venture Capital Governance. Private versus Labour Sponsored Venture Capital Funds, February 2003

854 Eckhard Janeba and John Douglas Wilson, Decentralization and International Tax Competition, February 2003

855 Tapio Palokangas, Capital Accumulation and Employment Cycles in a Model of Creative Destruction, February 2003

856 Brendan Walsh, When Unemployment Disappears: Ireland in the 1990s, February 2003

857 Luis H. R. Alvarez and Erkki Koskela, A General Approach to the Stochastic Rotation Problem with Amenity Valuation, February 2003

858 Christian Schultz, Strategic Campaigns and Redistributive Politics, February 2003

859 Ernst Fehr and Joseph Henrich, Is Strong Reciprocity a Maladaptation? On the Evolutionary Foundations of Human Altruism, February 2003

860 Haizhou Huang, Dalia Marin, and Chenggang Xu, Financial Crisis, Economic Recovery and Banking Development in Former Soviet Union Economies, February 2003

861 Pedro Cardoso and Bernard M.S. van Praag, How Sustainable Are Old-age Pensions in a Shrinking Population with Endogenous Labour Supply?, February 2003

862 Volker Meier, Efficient Transfer of Aging Provisions in Private Health Insurance, February 2003

863 Edward Castronova, Theory of the Avatar, February 2003

864 Robert S. Chirinko, Hans van Ees, Harry Garretsen, and Elmer Sterken, Investor Protections and Concentrated Ownership: Assessing Corporate Control Mechanisms in the Netherlands, February 2003

865 Bernard M.S. van Praag and Pedro Cardoso, The Mix Between Pay-as-you-go and Funded Pensions and what Demography has to do with it, February 2003

866 Ernst Fehr, Urs Fischbacher, Bernhard von Rosenbladt, Jürgen Schupp, and Gert G. Wagner, A Nation-Wide Laboratory. Examining Trust and Trustworthiness by Integrating Behavioral Experiments into Representative Survey, February 2003

867 Frank Heinemann, The Inflationary Impact of Wage Indexation, February 2003

868 Eytan Sheshinski, Bounded Rationality and Socially Optimal Limits on Choice in a Self-Selection Model, February 2003 
869 M. Hashem Pesaran, Estimation and Inference in Large Heterogenous Panels with Cross Section Dependence, February 2003

870 Luis H. R. Alvarez and Erkki Koskela, On the Tree-Cutting Problem under Interest Rate and Forest Value Uncertainty, February 2003

871 Norbert Berthold and Rainer Fehn, Unemployment in Germany: Reasons and Remedies, February 2003

872 Clemens Fuest, Bernd Huber, and Philipp Tilleßen, Tax Policy and Entrepreneurship in the Presence of Asymmetric Information in Capital Markets, February 2003

873 Eytan Sheshinski, Optimum and Risk-Class Pricing of Annuities, February 2003

874 Willi Leibfritz, Paul O'Brien and Jean-Christophe Dumont, Effects of Immigration on Labour Markets and Government Budgets - An Overview, February 2003

875 M. Hashem Pesaran and Allan Timmermann, How Costly is it to Ignore Breaks when Forecasting the Direction of a Time Series?, February 2003

876 Thorvaldur Gylfason and Gylfi Zoega, Education, Social Equality and Economic Growth: A View of the Landscape, February 2003

877 Robin Boadway and Jean-François Tremblay, Public Economics and Startup Entrepreneurs, February 2003

878 Erkki Koskela and Roope Uusitalo, The Un-Intended Convergence: How the Finnish Unemployment Reached the European Level, February 2003

879 Robert Fenge and Volker Meier, Pensions and Fertility Incentives, February 2003

880 Eytan Sheshinski, Note on Income Taxation and Occupational Choice, February 2003

881 A B Atkinson, Income Inequality in OECD Countries: Data and Explanations, February 2003

882 Thomas Gehrig and Rune Stenbacka, Venture Cycles: Theory and Evidence, February 2003

883 Ralf Becker and Thomas Hellmann, The Genesis of Venture Capital - Lessons from the German Experience, March 2003

884 Eytan Sheshinski, Note on the Optimum Pricing of Annuities, March 2003

885 Paul De Grauwe and Magdalena Polan, Globalisation and Social Spending, March 2003

886 F. van der Ploeg, Do Social Policies Harm Employment and Growth?, March 2003

887 Mirjam van Praag, Initial Capital Constraints Hinder Entrepreneurial Venture Performance: An empirical analysis, March 2003 
888 Bernard Steunenberg, Coordinating Sectoral Policymaking: Searching for Countervailing Mechanisms in the EU Legislative Process, March 2003

889 Eytan Sheshinski, Optimum Delayed Retirement Credit, March 2003

890 Frederick van der Ploeg, Rolling Back the Public Sector - Differential effects on employment, investment and growth, March 2003

891 Paul De Grauwe and Marc-Alexandre Sénégas, Monetary Policy in EMU when the Transmission is Asymmetric and Uncertain, March 2003

892 Steffen Huck and Kai A. Konrad, Strategic Trade Policy and the Home Bias in Firm Ownership Structure, March 2003

893 Harry Flam, Turkey and the EU: Politics and Economics of Accession, March 2003

894 Mathias Hoffmann and Ronald MacDonald, A Re-examination of the Link between Real Exchange Rates and Real Interest Rate Differentials, March 2003

895 Badi H. Baltagi, Espen Bratberg, and Tor Helge Holmås, A Panel Data Study of Physicians' Labor Supply: The Case of Norway, March 2003

896 Dennis C. Mueller, Rights and Citizenship in the European Union, March 2003

897 Jeremy Edwards, Gains from Trade in Tax Revenue and the Efficiency Case for Trade Taxes, March 2003

898 Rainer Fehn and Thomas Fuchs, Capital Market Institutions and Venture Capital: Do They Affect Unemployment and Labour Demand?, March 2003

899 Ronald MacDonald and Cezary Wójcik, Catching Up: The Role of Demand, Supply and Regulated Price Effects on the Real Exchange Rates of Four Accession Countries, March 2003

900 R. Selten, M. Schreckenberg, T. Pitz, T. Chmura, and S. Kube, Experiments and Simulations on Day-to-Day Route Choice-Behaviour, April 2003

901 Stergios Skaperdas, Restraining the Genuine Homo Economicus: Why the Economy Cannot be Divorced from its Governance, April 2003

902 Yin-Wong Cheung, Menzie D. Chinn, and Antonio Garcia Pascual, What Do We Know about Recent Exchange Rate Models? In-Sample Fit and Out-of-Sample Performance Evaluated, April 2003

903 Mika Widgrén, Enlargements and the Principles of Designing EU - Decision-Making Procedures, April 2003 